\title{
AVALIAÇÃO FUNCIONAL DA TERAPIA AUTÓLOGA DE CÉLULAS DERIVADAS MEDULA ÓSSEA, FRAÇÃO MONONUCLEAR NO TRAUMA CRÔNICO DA MEDULA ESPINAL - MODELO EXPERIMENTAL EM ANIMAIS
}

\author{
Functional assessment of autologous bone marrow cell therapy, mononuclear fraction \\ on Chronic Spinal Cord injury: An experimental animal model
}

\author{
Katherine Athayde Teixeira de Carvalho ${ }^{1-2}$, Emiliano Neves Vialle ${ }^{3}$, Guilherme Henrique Gonçalves Moreira ${ }^{1}$, Julio César \\ Francisco', Rossana Baggio Simeoni', Leila de Oliveira', Ricardo Corrêa Cunha ${ }^{4}$, Luiz Cesar Guarita-Souza', \\ Márcia Olandoski', Luiz Roberto Gomes Vialle ${ }^{1}$
}

\begin{abstract}
RESUMO
O implante de diversos tipos celulares tem sido proposto para o tratamento de lesão da medula espinal após trauma, visando sua regeneração funcional. Objetivos: Avaliar os efeitos funcionais da terapia autóloga de células derivadas da medula óssea, fração mononuclear no trauma crônico da medula espinal. Métodos: 70 ratos foram submetidos à lesão da medula espinal por impacção, sendo avaliados diariamente quanto à função motora, com o auxílio de escala motora de Basso, Beatie e Bresnahan a cada 48 horas, durante a pesquisa. Catorze dias depois, os animais com escore $\leq 16$ foram divididos de modo aleatório em dois grupos: Controle (veículo) versus Estudo (células), aos quais foram administradas injeções no parênquima da medula espinal de acordo com o grupo, e avaliados por dez dias a partir do implante, seguido de eutanásia. As células derivadas da medula óssea, fração mononuclear, foram isoladas e obtidas por punção-aspiração da medula óssea, seguido de gradiente de densidade $\left(\mathrm{d}=1,077 \mathrm{~g} / \mathrm{m}^{3}\right)$. Análise estatística: em relação aos escores percentuais, as comparações foram realizadas entre os grupos: teste não-paramétrico de Mann-Whitney, e para as comparações dentro dos grupos: teste não-paramétrico de Wilcoxon. Resultados: Dos 70 animais, 24 obtiveram escore $\leq 16$, sendo submetidos à pesquisa: grupo Controle ( $\mathrm{n}=11$ ) e grupo Estudo $(\mathrm{n}=13)$. Destes, 7 e 11, respectivamente, terminaram a pesquisa. As análises estatísticas não demonstraram significância para ambos os testes entre os dois grupos ( $p>.05)$. Conclusão: O implante de células derivadas da medula óssea, sua fração mononuclear não demonstrou ser funcionalmente efetiva no trauma crônico da medula espinal, no modelo proposto.
\end{abstract}

Descritores: Trauma da medula espinal, implante, células da medula óssea, ratos.

\footnotetext{
Instituições:

1 Instituto de Ciências Biológicas e da Saúde, da Pontifícia Universidade Católica do Paraná (ICBS-PUCPR) - Curitiba

2 Instituto Pelé Pequeno Príncipe (Complexo Hospitalar Pequeno Príncipe) - Curitiba

${ }^{3}$ Hospital Cajuru (PUCPR) - Curitiba

${ }^{4}$ Centro de Estudos da Performance Física (UFPR) - Curitiba
}

\section{Correspondência:}

Katherine Athayde Teixeira de Carvalho

Alameda Carlos de Carvalho, 655 / 1405 - Centro

CEP 80430-180 - Curitiba - Paraná

Tel./Fax: 5541 3223-1689

E-mail: katherincarv@gmail.com

Recebido em: 05.09.2006

Aceito em: 28.02 .2007

\section{INTRODUÇÃO}

A lesão da medula espinal traumática (LMT) é uma das mais devastadoras entre as lesões que afetam o ser humano.

A LMT atinge principalmente a faixa etária mais exposta a acidentes, que, em geral, é também a mais produtiva. Cerca de $60 \%$ dos casos de LMT ocorrem em pessoas entre 16 e 30 anos de idade, mas a média vem crescendo com o aumento da longevidade do ser humano, chegando a 38 anos na última década. ${ }^{1}$

O tratamento se faz atualmente através da prevenção da lesão progressiva pós-trauma e da restauração de neurônios danificados. ${ }^{2}$ Vários estudos demonstraram o efeito protetor dos corticóides, em particular da metilprednisolona, quando utilizada nas primeiras oito horas após o trauma, demonstrando que o dano medular é progressivo, podendo ser reduzido com tratamento adequado. ${ }^{3}$

No campo da regeneração, novas técnicas de biologia molecular que identificam e sintetizam proteínas com a atividade do fator de crescimento neuronal têm sido aplicadas com sucesso em ratos. ${ }^{4}$ 
A maior parte das pesquisas que apresentaram resultados aplicáveis ao ser humano foi realizada em pequenos animais em etapa préclínica, sendo que os principais estudos na área de trauma da medula espinal concentraram esforços para a padronização de um modelo semelhante ao do trauma do ser humano. Desta maneira, os tratamentos propostos são testados, supostamente, sobre portadores de lesões idênticas, o que torna as análises mais confiáveis. Os pesquisadores admitem que o melhor animal para essas experiências é o rato, sendo que a única forma de comparar resultados é a partir de lesões padronizadas e em grande número de espécimes. ${ }^{5,6,7,8}$

Por outro lado, a pesquisa de regeneração tecidual utiliza vários tipos celulares provenientes ou não da medula óssea. Em particular, pelo fácil acesso e obtenção de células derivadas da medula óssea, elas são muito estudadas, inclusive para outras doenças. As células da medula óssea, fração mononuclear apresentam duas características: capacidade de renovação das linhagens hematopoiéticas e mesenquimais, sendo que a linhagem mesenquimal possui a potencialidade de originar vários tipos celulares maduros com características morfológicas e funções especializadas. As funções primárias de células da medula óssea, fração mononuclear são de homeostase sanguínea, através de proliferação dos precursores da linhagem hematopoiética e da linhagem mesenquimal para os tecidos derivados do mesênquima e, com certas limitações, na dependência da reprogramação nuclear. .,10,11,12 $^{2}$

Além disso, as células mesenquimais estão dispersas nos tecidos maduros internos, atuando de formas diversas, dependendo do local onde são desenvolvidas. Descobertas recentes têm demonstrado o grande potencial clínico-regenerativo das células mesenquimais, inclusive nas provenientes do tecido adiposo, existindo potencial de diferenciação até para progenitores neurais. ${ }^{13-14}$

Baseando-se no princípio de que as células mesenquimais são pluripotentes contendo sub-populações celulares capazes de se diferenciarem de acordo com o meio in vitro, espera-se que as células derivadas da medula óssea, sua fração mononuclear, quando transplantadas por interação celular tecidual in vivo, sejam capazes de diferenciarem-se em células do tecido no qual foi transplantada e regenerando-o, inclusive com recuperação funcional. ${ }^{11}$

Desta forma, propomos a utilização do modelo de lesão crônica da medula espinal pela impacção (contusão), para analisar os efeitos clínicos da terapia celular por implante de células derivadas da medula óssea: fração mononuclear através de implante intraparenquimatoso.

\section{MÉTODO}

Os experimentos foram realizados seguindo as normas e princípios éticos do Colégio Brasileiro de Experimentação Animal, tendo sido aprovado pelo Comitê de Ética de Experimentação Animal (CEEA) do Setor de Ciências Biológicas da UFPR (processo: 23075.047723/2007-89).

Procedimento cirúrgico: Foram utilizados 70 ratos Wistar machos (260-300g) provenientes do Biotério Central da PUC$\mathrm{PR}$. Os ratos foram armazenados em gaiolas de polipropileno, agrupados em dupla sob ciclos claro/escuro (12/12h). Todos os animais foram alimentados com água e ração. Os animais foram anestesiados com ketamina $(80 \mathrm{mg} / \mathrm{kg}$, i.p.) e xilazina (10 $\mathrm{mg} / \mathrm{kg}$, i.p.). A antibiótica-terapia profilática foi realizada com cefalotina $1 \mathrm{mg} / \mathrm{kg}$. O dorso de cada animal foi depilado, sendo

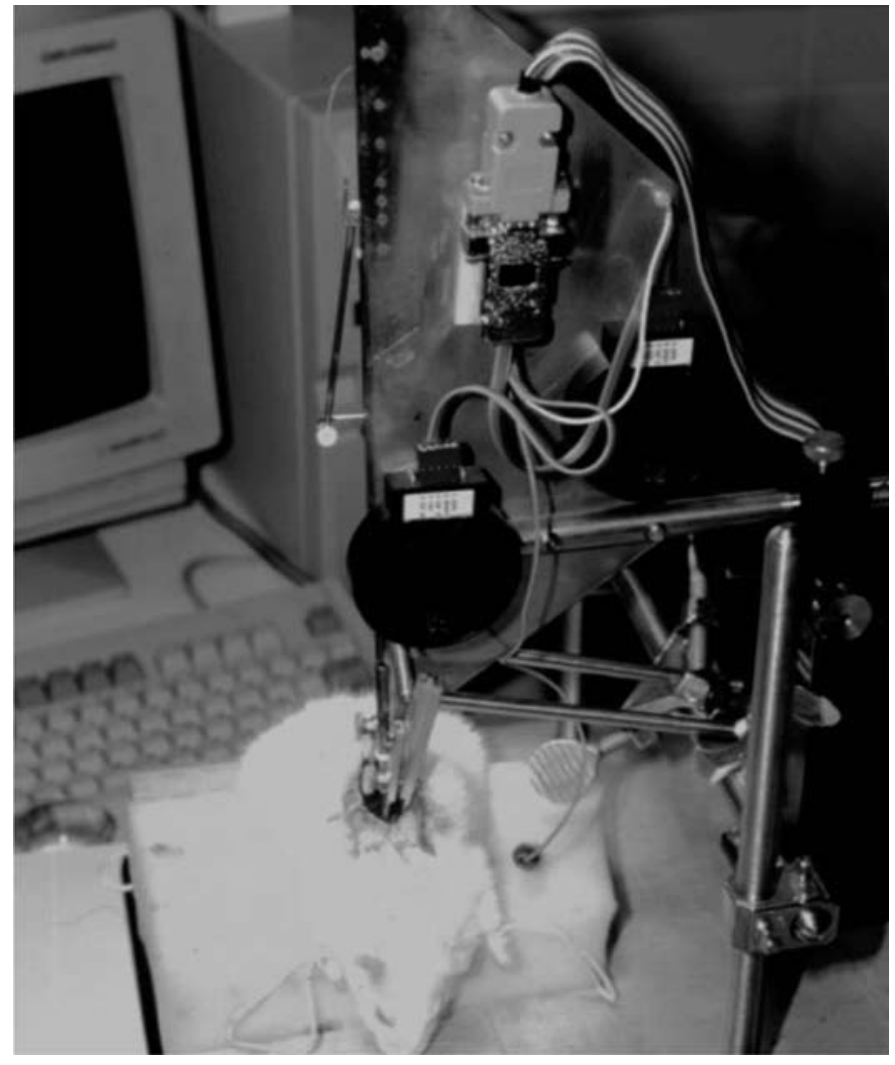

Figura 1: Aparelho Impactor NYU: Queda de uma barra de $10 \mathrm{~g}$ de uma altura de $12,5 \mathrm{~mm}$ em uma área seccional de $2 \mathrm{~mm}^{2}$ da medula espinal nível T9 e T10 após a laminectomia dorsal.

estes posicionados em decúbito ventral. Foi realizada no dorso de cada animal, após a anti-sepsia de pele, uma incisão longitudinal mediana de $5 \mathrm{~cm}$, sendo a musculatura paravertebral afastada e seguida de laminectomia de T9-T10.

A lesão contusa da medula espinal foi provocada pela queda de uma haste de $10 \mathrm{~g}$ de uma altura de $12.5 \mathrm{~mm}$, em área seccional de $2 \mathrm{~mm}^{2}$, pelo aparelho Impactor New York University (INYU) (Figura 1). ${ }^{8}$ Após esse procedimento, todos os animais foram acompanhados diariamente, realizando-se a expressão vesical manual pelo método de Crede, $8 / 8 \mathrm{~h}$, e análise motora com o auxílio do escore motor de Basso, Beatie e Bresnahan (B.B.B.) realizado a cada 48 horas. Esse escore consiste numa escala que varia de zero a 21, sendo zero a ausência total de movimentos, e 21 a presença de movimentos normais (Anexo I). ${ }^{15}$

Obtenção do sangue da medula óssea: Para cada animal, a obtenção do sangue da medula óssea foi realizada pelo método de punção-aspiração na medula óssea dos ratos, sempre precedida de anestesia: Ketamina $50 \mathrm{mg} / \mathrm{Kg}$ e Xilazina $10 \mathrm{mg} / \mathrm{Kg}$. Os animais foram colocados em posição de decúbito lateral com a perna superior flexionada e a inferior reta. A punção-aspiração foi realizada na crista ilíaca posterior do fêmur por seringa descartável (BD-Plastipak $^{\circledR}$ ) de $5 \mathrm{~mL}$, com $0,2 \mathrm{~mL}$ de heparina $(5.000 \mathrm{UI} / \mathrm{mL}$ ), com agulha 25X8 $21 \mathrm{~mm}$ G1 (BD- Precision Glide ${ }^{\circledR}$ ); foi coletado cerca de $1 \mathrm{~mL}$ do sangue da medula óssea de cada rato, seguida de identificação das seringas. 
Figura 2: Histogramas dos resultados de citometria de fluxo: células mononucleares derivadas da medula óssea. $C D 45^{+}$e CD34.

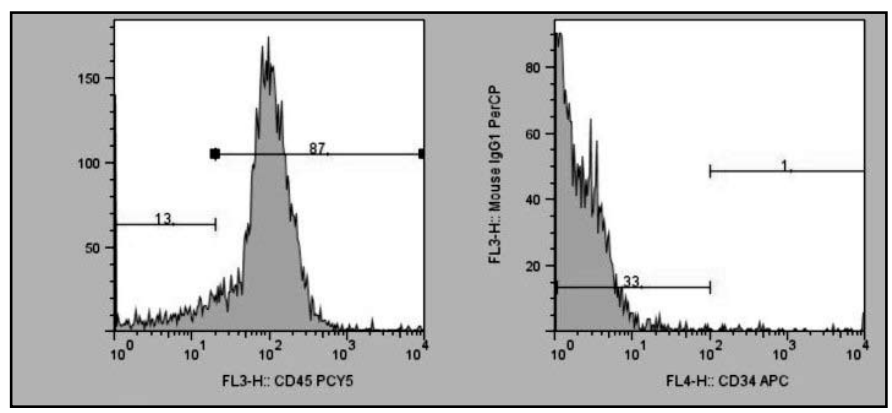

Isolamento das células da medula óssea, fração mononuclear: O material obtido na técnica de punção-aspiração foi levado sob o fluxo laminar à cabine de segurança biológica de classe II. Todas as soluções utilizadas no processo foram rigorosamente controladas quanto à esterilidade e composição.

No isolamento da fração mononuclear utilizou-se o gradiente de densidade $\left(\mathrm{d}=1,077 \mathrm{~g} / \mathrm{m}^{3}\right)$ (Ficoll-Hypaque -Sigma, St. Loius, MO) e o Meio de Dulbecco modificado por Iscove (IMDM-GIBCO BRL) suplementado com $1 \%$ de antibiótico (penicilina e estreptomicina) e $20 \%$ de solução tampão. Ao material coletado foram adicionados $9 \mathrm{~mL}$ de meio IMDM, acrescentados 3mL de Ficoll-Hypaque e então centrifugado por 40 minutos a $400 \mathrm{~g}$ em temperatura de $18^{\circ} \mathrm{C}$. Após a centrifugação, $5 \mathrm{~mL}$ foram aspirados da camada de plasma junto ao meio e descartados, seguido da remoção cuidadosa do anel de células de aspecto esbranquiçado, sendo transferido para outro tubo de $15 \mathrm{~mL}$ completando o volume com o meio, seguido de centrifugação a $400 \mathrm{~g}$ por dez minutos. O sobrenadante foi então desprezado e o precipitado foi re-suspenso no meio IMDM e novamente centrifugado a $400 \mathrm{~g}$ por dez minutos, sendo retirado e desprezado o sobrenadante. ${ }^{16}$ Seguiram-se as contagens diretas de células no hemocitômetro com o auxílio do azul de Trypan. As amostras de células foram analisadas por imunofenotipagem, com o auxílio de citometria de fluxo (FACScalibur Becton-Dickson), para marcadores anti-CD45 (PE-Cy5[ Clone OX-1] Becton and Dickson-USA) e anti-CD34 (APC[clone 58], Becton and DicksonUSA) e caracterização destas como CD45 ${ }^{+}$e CD34- (Figura 2).

Implante: As células derivadas da medula óssea, fração mononuclear foram suspensas no IMDM, contendo $20 \%$ de soro bovino fetal (SBF, Gibco BRL, Grand Island, NY) e 1\% de antibiótico $(100 \mu \mathrm{g} /$ $\mathrm{mL}$ de penicilina e $100 \mu \mathrm{g} / \mathrm{mL}$ estreptomicina).

O implante foi realizado 14 dias após a lesão no parênquima medular espinal no nível T09-T10 (Figura 3).

A concentração celular para o grupo de Estudo foi de $10^{5}$, sendo o volume de $150 \mu \mathrm{L}$ para ambos os grupos. A infusão foi por meio de seringa descartável 100U/1mL com agulha 30G1/2.

Eutanásia e fixação de tecido: Após dez dias do implante, a eutanásia dos animais foi realizada com auxílio de tiopental ( $100 \mathrm{mg} / \mathrm{kg}$, i.p.), seguida de ex-sanguínea completa e de infusão de $300 \mathrm{~mL}$ de solução formalina $10 \%$ tamponada para a fixação.

Análise estatística: Na comparação dos grupos controle e estudo, as diferenças foram consideradas nos escores percentuais em relação à avaliação basal (após o trauma e antes do implante), tendo sido usado o teste não-paramétrico de Mann-Whitney. Nas comparações entre os grupos em relação aos escores percentuais, e para as comparações entre a avaliação basal e as avaliações após dez dias de implante dentro dos grupos, foi realizado o teste nãoparamétrico de Wilcoxon.

\section{RESULTADOS}

Dos 70 ratos lesados, 48 sobreviveram para as análises, sendo que 30 animais obtiveram escore $\leq 16$ e destes, seis foram excluídos da análise por condições deletérias: autofagia e infecções. Os 24 animais foram então divididos de modo aleatório para os grupos: Estudo ( $\mathrm{n}=13)$ e Controle ( $\mathrm{n}=11)$. Quatro animais do grupo Controle e dois do grupo Estudo morreram após a terapia, terminando sete animais do grupo controle $(63,6 \%)$ e 11 do grupo terapia $(84,6 \%)$. As análises estatísticas não demonstraram significância: $p>.05$ para ambos os testes (Figuras 4 e 5). Complicações foram observadas nos animais: autofagia $(8,6 \%)$ e oclusão das vias urinárias $(11,4 \%)$, ambos do total de animais lesados.

\section{DISCUSSÃO}

As células-tronco derivadas da medula óssea adultas, fração mononuclear apresentam sub-frações de 0,001\%-0,01\% de células pluripotentes (células-tronco mesenquimais derivadas da medula óssea) e, para obter resultados benéficos, talvez haverá necessidade de transplantar maior número de células-tronco mesenquimais ou de células-tronco mesenquimais já diferenciadas para a linhagem neuronal. ${ }^{11}$

As injeções no parênquima medular espinal foram traumáticas, demonstrado pelo decréscimo do escore clínico 24 hs após a terapia celular; no entanto, essa via de administração garantiu a entrega das células no local da lesão (Figura 4).

O trauma inerente ao ato da terapia celular poderá ser minimizado com a utilização de seringa de Hamilton (modelo 702) e respectiva agulha: "gauge" 22S "Point" -4 e conseqüentemente, menor volume com veículo: $15 \mu \mathrm{L}$, pois a própria difusão do veículo poderia explicar o decréscimo do escore clínico após a terapia, considerando-se uma injúria tecidual adicional.

Nossos resultados assemelham-se aos resultados recém-publicados com o modelo de secção completa da medula por clipagem e

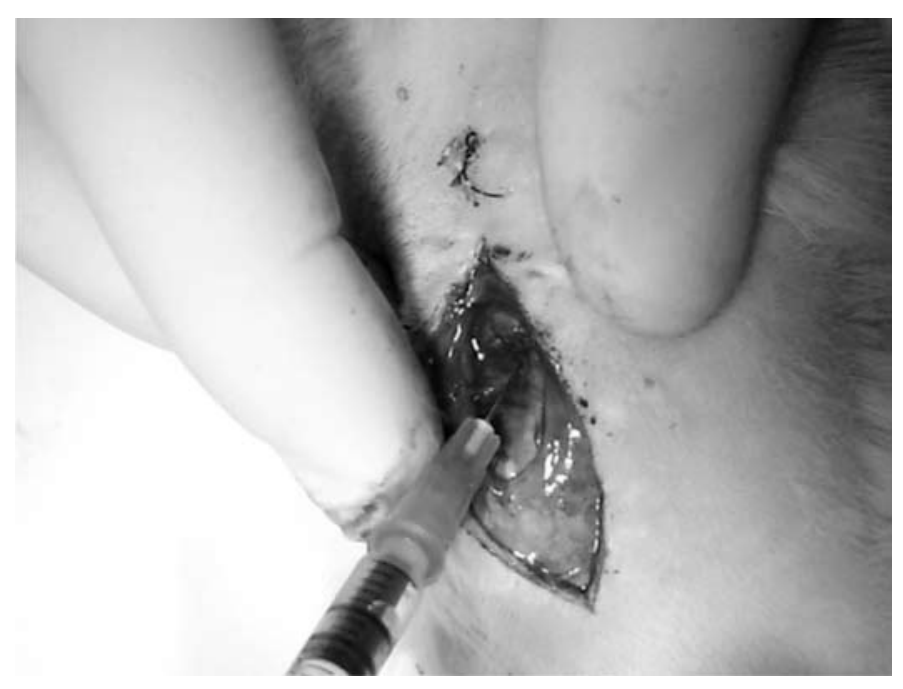

Figura 3: Injeção intraparequimatosa na medula espinal nível T09-T10. 
Figura 4: Nas comparações entre grupos em relação aos escores percentuais foi usado o teste não-paramétrico de Mann-Whitney, e nas comparações entre a avaliação basal e a avaliação após 10 dias de terapia dentro dos grupos, foi aplicado o teste não-paramétrico de Wilcoxon. Para ambos os testes não houve significância (ns) estatística: $\boldsymbol{p}>05$.

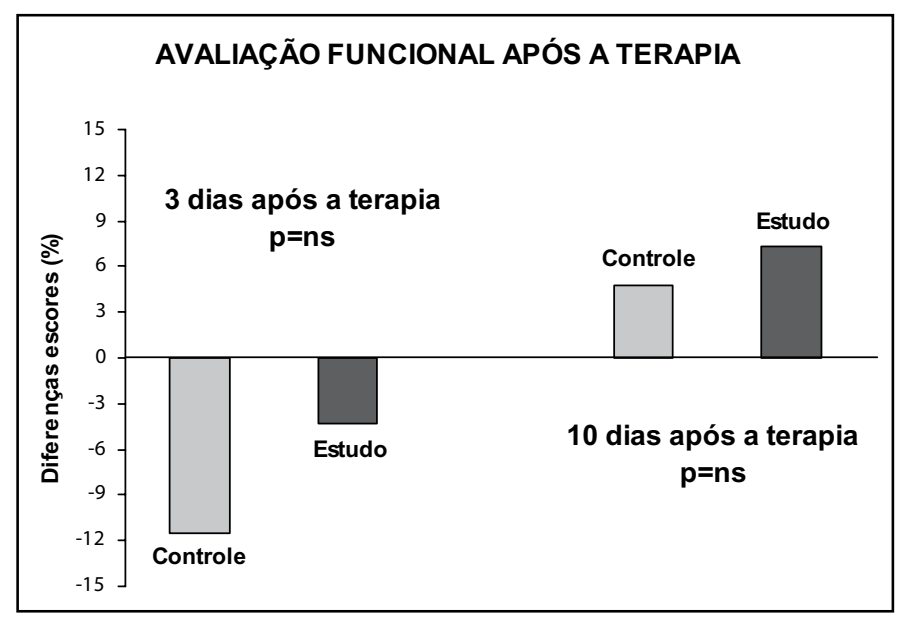

Figura 5: Teste exato de Fisher. Valores de p.>05 indicaram ausência de significância estatística (ns).

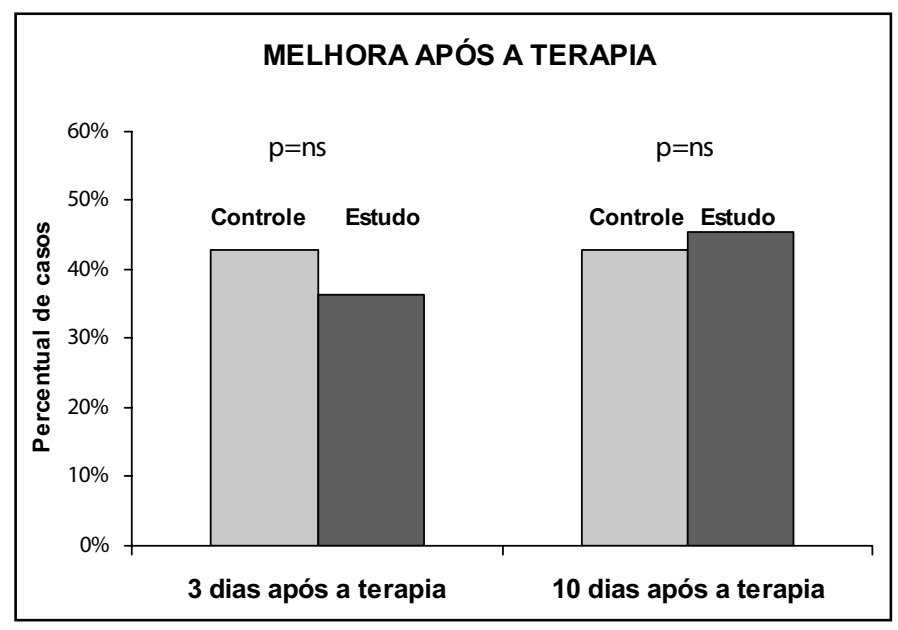

descartando a possibilidade desse tratamento com células adultas derivadas da medula óssea, sua fração mononuclear, no trauma crônico da medula espinal, e afastando a transferência desse modelo de terapia assim proposto para o ser humano. ${ }^{17}$

Salientamos que este trabalho deu início a uma linha de pesquisa de terapia celular associada ao modelo de lesão por contusão (etapa pré-clínica) para testarmos outros tipos celulares. Nossos resultados não invalidam a possibilidade de resultados benéficos no trauma agudo da medula espinal.

\section{CONCLUSÃO}

O implante de células derivadas da medula óssea, sua fração mononuclear não demonstrou ser funcionalmente efetivo no trauma crônico da medula espinal, no modelo proposto.

\section{AGRADECIMENTOS}

Ao Dr. Alberto Veiga Accioly pelo apoio institucional da PUCPR.

\section{ANEXO I \\ Escala Basso, Beatie and Bresnahan (B.B.B.) ${ }^{15}$}

A escala de BBB observa os movimentos da articulação do quadril, joelho, tornozelo, posição do tronco, rabo e patas traseiras. A partir dessas observações, foram atribuídos pontos de zero a 21 , sendo que zero correspondente à ausência total de movimentos e 21 à presença de movimentos normais.

0 - não observação de movimento nos membros posteriores (MP).

1 - suave movimento de uma ou duas articulações, normalmente do quadril e/ou joelho.

2 - extenso movimento de uma articulação ou extenso movimento de uma articulação e suave movimento de outra articulação.

3 - extenso movimento de duas articulações do MP.

4 - suave movimento de mais de três articulações MP.

5 - suave movimento de duas articulações e extenso movimento de uma terceira.

6 - extenso movimento de duas articulações e suave movimento de uma terceira ou extenso movimento nas três articulações do MP.

7 - largo movimento com nenhum peso de suporte ou colocação plantar da pata com nenhum peso de suporte.

8 - sustentação plantar da pata com peso suporte em postura (quando parado) ou ocasional, freqüente, ou consistente suporte de peso na passada dorsal e nenhum apoio nas passadas plantares, movimentos suaves sem suportar o peso do corpo.

9 - ocasional suporte de peso na passada plantar, nenhum MA (membros anteriores)-MP coordenação.

10 - freqüência constante do suporte de peso na passada plantar, nenhuma MA-MP coordenação.

11- freqüência constante do suporte de peso na passada plantar e ocasional MA (movimento anterior) de coordenação.

12- freqüência constante do suporte de peso na passada plantar e freqüente MA-MP de coordenação.

13- constante suporte de peso na passada plantar, constante MSMP de coordenação;

14- constante passada plantar e constante MA-MP com coordenação e predominância da posição das patas em rotação (interna ou externa) quando começa o contato inicial com a superfície antes mesmo de levantar no fim da postura ou freqüente passada plantar, constante MA-MP com coordenação e ocasional passada dorsal.

15- constante passada plantar e constante MA-MP coordenados; e nenhum movimento dos dedos dos pés ou ocasional movimento dos dedos dos pés durante o avanço do membro seguinte. Predominante posição da pata, paralela ao corpo no contato inicial.

16- constante passada plantar e constante coordenação MA-MP durante o andar; e dedos dos pés livres ocorrem freqüentemente durante o avançar dos membros dianteiros predominantemente as posições das patas estão paralelas no contato inicial e rodado ao se levantar.

17- constante passada plantar e constante coordenação MA-MP durante o andar; e os dedos dos pés estão livres freqüentemente 
durante o avançar dos membros dianteiros e a posição das patas estando paralelas no contato e ao levantar-se.

18- constante passada plantar e constante coordenação MA-MP durante o andar; os dedos dos pés livres ocorrem constantemente durante o avançar dos membros dianteiros predominantemente; a posição das patas estão paralelas no contato inicial e rodada ao levantar-se.

19- constante passada plantar e constante coordenação MA-MP durante o andar, os dedos dos pés livres ocorrem constantemente durante o avançar dos membros dianteiros predominantemente; a posição das patas estão paralelas no contato inicial e ao levantar-se; o rabo mantém-se para baixo o tempo todo ou apenas parte dele.

20- constante passada plantar e constante coordenação ao andar, constante movimento livres dos dedos dos pés; predominantemente, as posições das patas estão paralelas no contato inicial e ao levantarse; instabilidade do tronco; rabo constantemente para cima.

21- constante passada plantar e andar coordenado, constantes movimentos livres dos pés, posição das patas predominantemente paralelas durante a postura, constante estabilidade de tronco, rabo constantemente para cima.

\section{ABSTRACT}

The cell therapy using several cell types has been proposed to promote regeneration after spinal cord injury. Purpose: To assess functional effects of the autologous bone marrow cells, mononuclear fraction transplantation in the chronic spinal cord trauma. Methods: 70 adults, male Wistar rats were submitted to spinal cord contusion injury by Impactor, being assessed every 48 hours using the Basso, Beatie and Bresnahan locomotor rating scale. After 14 days, those animals with score $\leq 16$ were randomly divided in two groups: Control (vehicle) versus Study (with parenchymal cell infusion), which were followed-up for 10 days. The bone marrow cells, mononuclear fraction (CD45 ${ }^{+}$ e CD34-) were attained and isolated by puncture-aspiration of the bone-marrow and by density gradient ( $\mathrm{d}=1.077)$. Statistics Analysis: as to the percentage scores, comparisons were performed between groups: non-parametric Mann-Whitney test, and for the comparison into groups: non-parametric Wilcoxon test. Results: From 70 animals, 24 rats attained $\leq 16$ scores, and were submitted to the therapy: Control group ( $\mathrm{n}=11)$, and Study group $(\mathrm{n}=13)$. From these, 7 and 11, respectively, ended the research. The statistical analysis did not show any significance: $p>.05$ in both tests. Conclusion: The bone marrow cell therapy, mononuclear fraction had not shown functional effectiveness in chronic spinal cord injury in this model.

Keywords: spinal cord, trauma, cell therapy, bone marrow, mononuclear cells, rat.

\section{REFERÊNCIAS}

1. National Spinal Cord Injury Statistical Center. J Spinal Cord Med. 2005:28(4):379-80.

2. Anderson DK, Braughler JM, Hall ED, Waters TR, McCall JM, Means ED. Effects of treatment with U-74006 on neurological outcome after experimental spinal cord injury. J Neurosurg. 1988;69(4):562-7.

3. Braughler JM, Hall ED. Lactate and pyruvate metabolism in injured cat spinal cord before and after a single large intravenous dose of methylprednisolone. .J Neurosurg. 1983;59(2):256-61.

4. Constantini S, Young W. The effects of methylprednisolone and ganglioside GM1 on acute spinal cord injury in rats. J Neurosurg. 1994;80(1):97-111.

5. Falconer JC, Narayana PA, Bhattacharjee M, Liu SJ. Characterization of an experimental spinal cord injury model using waveform and morphometric analysis. Spine. 1996;21(1):104-12.

6. Noble LJ, Wrathall JR. Spinal cord contusion in the rat: morphometric analyses of alterations in the spinal cord. 1985; Exp. Neurol. 88(1):135-49.

7. Wrathall JR, Petegrew RK, Harvey F. Spinal cord contusion in the rat: production of graded, reproducible, injury groups. 1985; Exp. Neurol, 88(1):108-22.

8. Vialle E, Vialle LRG, Razera E, Cechinel C, Leonel I, Seyboth C. Avaliação da recuperação motora em ratos submetidos a lesão medular experimental. 1999; Rev Bras Ortop, 34:85-9.

9. Hermann A, Gastl R, Liebau S, Popa MO, Fiedler J, Boehm BO et al. Efficient generation of neural stem cell-like cells from adult human bone marrow stromal cells. 2004; J Cell Sci. 117(Pt19):4411-22.
10. Hofstetter CP, Schwarz EJ, Hess D, Widenfalk J, El Manira A, Prockop DJ et al. Marrow stromal cells form guiding strands in the injured spinal cord and promote recovery. PNAS. 2002;99(4):2199-204.

11. Verfaillie, CM Adult stem cells: assessing the case for pluripotency. Trends Cell Biol. 2002;12(11):502-8.

12. Jaenisch R, Young R. Stem Cells, the Molecular Circuitry of Pluripotency and Nuclear Reprogramming. Cell. 2008;132:567-82,

13. Zuk PA, Zhu M, Mizuno H, Huang J, Futrel JW, Katz AJ et al. Multilineage Cells from human adipose tissue: implications for cell-based therapies. Tissue Eng. 2001;7:211-28.

14. Ashian PH, Elbarbary AS, Edmonds B, Deugarte,D, Zhu M, Zuk PA et al. In vitro differentiation of human processed lipoaspirate cells into early neural progenitors. Plast Reconstrr Surg. 2003;111:1931-92.

15. Basso DM, Beattie MS, Bresnahan JC. A sensitive and reliable locomotor rating scale for open field testing in rats. J. Neurotrauma. 1995;12:1-21.

16. Boyum A. Isolation of mononuclear cells and granulocytes from human blood. Isolation of monuclear cells by one centrifugation and of granulocytes by combining centrifugation and sedimentation at 1g. Scand J Clin Lab Invest Suppl. 1968;97:77-89.

17. Roussos I, Rodriguez M, Villan D, Ariza A, Rodriguez L, Garcia J. Development of a rat model of spinal cord injury and cellular transplantation. Transplant Proc., 2005;37(9):4127-30. 